\title{
Assessing clinicopathological correlation in chronic traumatic encephalopathy: rationale and methods for the UNITE study
}

Jesse Mez ${ }^{1,2+}$, Todd M. Solomon ${ }^{1 \dagger}$, Daniel H. Daneshvar ${ }^{1,3+}{ }^{\dagger}$, Lauren Murphy ${ }^{1,2}$, Patrick T. Kiernan ${ }^{1,2}$, Philip H. Montenigro 1,4, Joshua Kriegel 1,2, Bobak Abdolmohammadi 1,2, Brian Fry ${ }^{1,2}$, Katharine J. Babcock ${ }^{1,2}$,

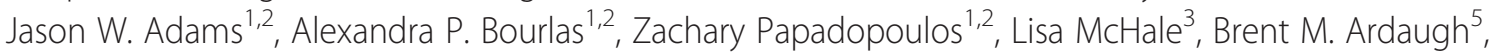
Brett R. Martin ${ }^{5}$, Diane Dixon ${ }^{5}$, Christopher J. Nowinski ${ }^{3}$, Christine Chaisson ${ }^{5}$, Victor E. Alvarez ${ }^{1,6,7,8}$, Yorghos Tripodis ${ }^{9}$, Thor D. Stein ${ }^{1,6,7,8}$, Lee E. Goldstein ${ }^{1,2}$, Douglas I. Katz ${ }^{2,10}$, Neil W. Kowall ${ }^{1,6,8,11}$, Robert C. Cantu ${ }^{1,2,3,12,13}$, Robert A. Stern ${ }^{1,2,4,12}$ and Ann C. McKee ${ }^{1,2,6,7,8,11^{*}}$

\begin{abstract}
Introduction: Chronic traumatic encephalopathy (CTE) is a progressive neurodegeneration associated with repetitive head impacts. Understanding Neurologic Injury and Traumatic Encephalopathy (UNITE) is a U01 project recently funded by the National Institute of Neurological Disorders and Stroke and the National Institute of Biomedical Imaging and Bioengineering. The goal of the UNITE project is to examine the neuropathology and clinical presentation of brain donors designated as "at risk" for the development of CTE based on prior athletic or military exposure. Here, we present the rationale and methodology for UNITE.

Methods: Over the course of 4 years, we will analyze the brains and spinal cords of 300 deceased subjects who had a history of repetitive head impacts sustained during participation in contact sports at the professional or collegiate level or during military service. Clinical data are collected through medical record review and retrospective structured and unstructured family interviews conducted by a behavioral neurologist or neuropsychologist. Blinded to the clinical data, a neuropathologist conducts a comprehensive assessment for neurodegenerative disease, including CTE, using published criteria. At a clinicopathological conference, a panel of physicians and neuropsychologists, blinded to the neuropathological data, reaches a clinical consensus diagnosis using published criteria, including proposed clinical research criteria for CTE.
\end{abstract}

Results: We will investigate the validity of these clinical criteria and sources of error by using recently validated neuropathological criteria as a gold standard for CTE diagnosis. We also will use statistical modeling to identify diagnostic features that best predict CTE pathology.

Conclusions: The UNITE study is a novel and methodologically rigorous means of assessing clinicopathological correlation in CTE. Our findings will be critical for developing future iterations of CTE clinical diagnostic criteria.

\footnotetext{
* Correspondence: amckee@bu.edu

${ }^{\dagger}$ Equal contributors

${ }^{1}$ Alzheimer's Disease Center, Boston University School of Medicine, 72 East

Concord Street, B-7800, Boston, MA 02118, USA

${ }^{2}$ Department of Neurology, Boston University School of Medicine, 72 East

Concord Street, Boston, MA 02118, USA

Full list of author information is available at the end of the article
} 


\section{Introduction}

Chronic traumatic encephalopathy (CTE) is a progressive neurodegenerative disease associated with repetitive head impacts (RHI) [1-6]. Currently, CTE can be diagnosed only pathologically, although clinical research criteria have been proposed $[5,7,8]$. The symptoms of CTE, originally known as "punch drunk" or "dementia pugilistica," were first described in 1928 in boxers [9]. Pathological evidence of CTE has been observed only in individuals with a history of head impacts that usually were repetitive. Examples of these impacts include those sustained during participation in contact sports, such as American football, soccer, rugby, ice hockey, and professional wrestling $[2,4,10-14]$; blast injuries sustained by military service members [3, 12, 15]; poorly controlled epilepsy; head-banging behaviors; and physical abuse [3, 16, 17].

The pathology of CTE is distinctive and clearly differentiated from other neurodegenerative diseases, such as Alzheimer's disease (AD) and frontotemporal lobar degeneration (FTLD) [10-12, 17-23]. Gross features of CTE pathology include atrophy of the cerebral cortex (especially the frontal and temporal lobes), diencephalon and mammillary bodies, and cavum septum pellucidum or septal fenestrations $[2,3,12,18]$.

Microscopically, CTE is characterized by the deposition of hyperphosphorylated tau ( $\mathrm{p}$-tau) as neurofibrillary tangles, astrocytic inclusions, and neurites irregularly distributed around small blood vessels, preferentially at the depths of cerebral sulci $[1-3,24,25]$. In well-established disease, the tau pathology is most prominent in the frontal and temporal lobes, hippocampus, amygdala, and entorhinal cortex [12, 19, 20].

Symptom onset in CTE usually does not immediately follow RHI, although the length of delay varies widely $[2,3,12,19]$. A constellation of cognitive, mood, and behavioral symptoms, including impulsivity, aggression, depression, apathy, suicidal ideation, episodic memory loss, and executive dysfunction, have been described $[1-5,12,26]$. Some individuals develop dementia as the disease progresses in severity. Motor symptoms, including gait instability, bradykinesia, and rigidity, are also common, usually late in the disease course $[1,3-5,12,26]$.

To date, understanding of the clinical presentation of CTE has come largely from clinicopathological case studies of individuals exposed to RHI based on clinical interviews with family members after the individuals' death $[4,26]$. Owing to the recall bias inherent to retrospective studies and the ascertainment bias associated with brain donation, there is a clear need for long-term, prospective, longitudinal studies. However, those studies will require a time period of nearly a decade or more before sufficient data can be generated to draw conclusions. As those longitudinal studies are developed, it is important to establish and refine consensus criteria for clinical and pathological CTE diagnosis and to continue gathering retrospective data to inform the long-term prospective studies. The imperative to continue analyzing clinical course and pathological correlates of CTE using cost-effective, efficient, and immediately feasible retrospective study designs is especially critical, given the potential long-term health risks of RHI.

Understanding Neurologic Injury and Traumatic Encephalopathy (UNITE) is a recently funded National Institutes of Health (NIH) U01 project in which researchers are examining the neuropathology and clinical symptoms of brain donors who have experienced RHI. The aim of the project is to study the relationship between clinical symptoms and the neuropathology of CTE.

Here, we present the methodology of the UNITE study for examining clinicopathological correlation. Specifically, we set forth the following aims: (1) to investigate the validity of recently proposed clinical criteria for CTE [5] using a clinical consensus meeting and recently validated neuropathological criteria for CTE ([2, 27], (A.C. McKee) as a gold standard for CTE diagnosis; (2) to identify sources of error between clinical consensus diagnosis and the neuropathological diagnosis of CTE; and (3) to identify individual diagnostic features that collectively best predict CTE pathology.

\section{Methods}

The institutional review board at the Boston University (BU) Medical Campus approved all of our research activities (IRB number 31614). Because all participants are deceased, consent does not need to be obtained. Figure 1 shows an overall flowchart of the study methodology. The presented methodology resulted from several iterations of updates based on investigator feedback.

\section{Study recruitment}

The U.S. Department of Veterans Affairs (VA)-BUConcussion Legacy Foundation (CLF) Brain Donation Registry and Brain Bank is a collaborative effort of the CTE Research Program within the BU Alzheimer's Disease Center (ADC), the VA Boston Healthcare System, and CLF, a non-profit organization dedicated to brain trauma research and education. Subject recruitment is ongoing and will occur throughout the 4-year study period. Figure 2 shows recruitment mechanisms in place since UNITE recruitment began in January 2014. For the majority of the brain donors, the subjects' next of kin contact the brain bank and agree to donate near the time of death. While living, some study subjects agree, through the Brain Donation Registry, to donate their brain and spinal cord after death. Potential subjects can register at any time, provided they meet specific inclusion and exclusion 


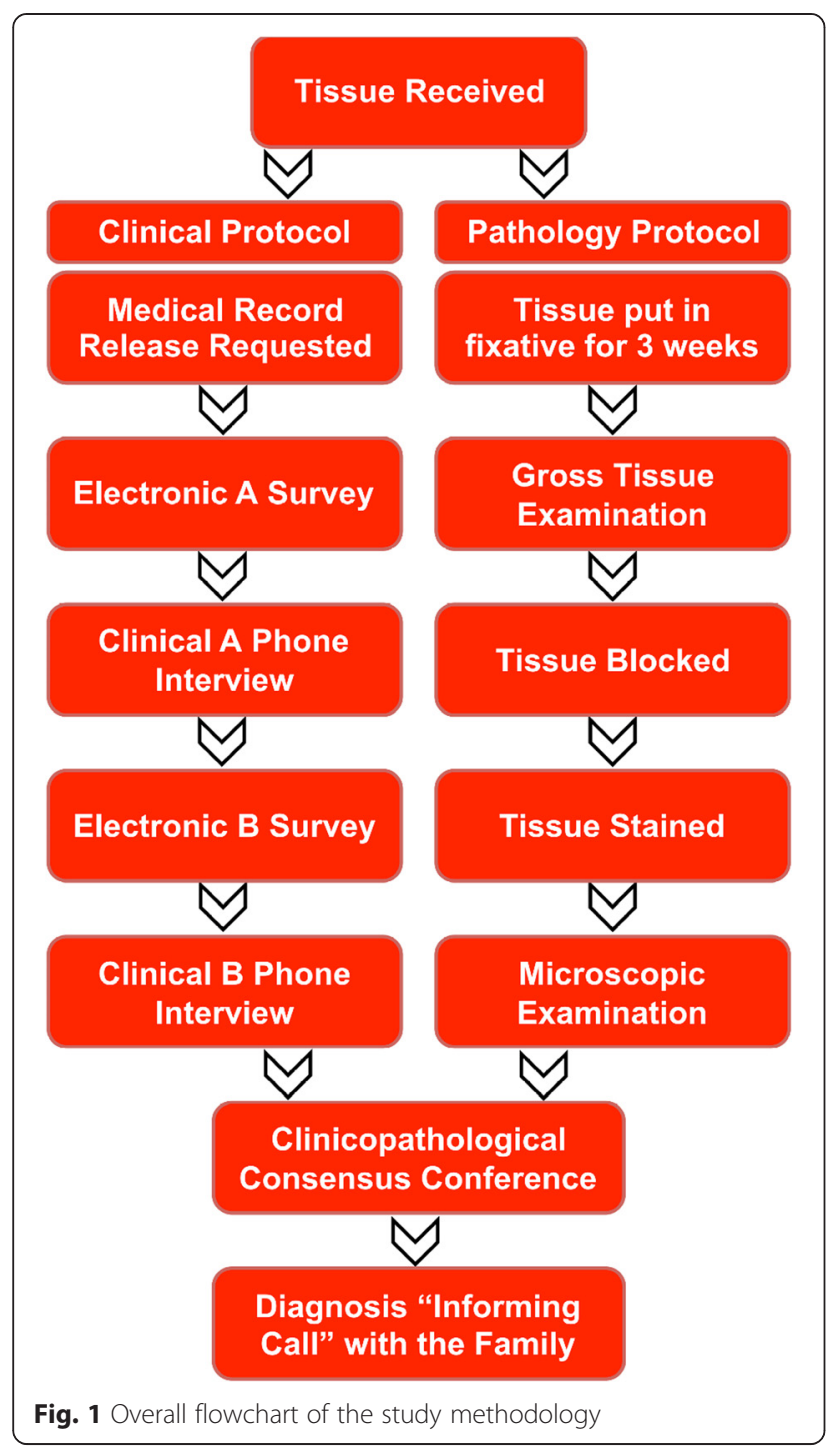

criteria (detailed below). The registry currently has nearly 600 potential living subjects. We anticipate that several hundred more will join the registry over the 4-year study period. On the basis of the rate of brain donation in recent previous work, we anticipate that 300 subject specimens will be donated over the 4-year study period, with $20 \%$ acquired through the registry.

\section{Eligibility criteria}

Regardless of recruitment mechanism, potential subjects are evaluated using the same inclusion and exclusion criteria (Table 1). The inclusion criteria are based solely on RHI exposure history, regardless of whether symptoms are present. The criteria allow for breadth of RHI exposure (e.g., athletics, military service, abuse) while requiring sufficient intensity such that there is a reasonable chance for the development of CTE (based on our experience, acknowledging that the relationship between
RHI and CTE is still under investigation). The inclusion criteria are broader for women, who historically have been investigated less thoroughly than men, and for individuals with amyotrophic lateral sclerosis (ALS), a particular research focus at our center. The exclusion criteria prevent inclusion of brain and spinal cord specimens of poor quality.

\section{Consent}

Consent for donation of brains and spinal cords is acquired from the decedent's legal next of kin or legally authorized representative (LAR). The next of kin or LAR also may consent for the donation of cerebrospinal fluid (CSF), blood, and/or eye tissue for use in related studies.

\section{Brain acquisition}

A member of the research team coordinates the extraction and shipment of the specimen. A properly trained individual (pathologist, medical examiner, autopsy technician, diener) extracts the tissue locally. If immediate shipment is possible, the specimen is placed on wet ice and shipped using a courier service to minimize the postmortem interval. If immediate shipment is not possible, the specimen is placed in $10 \%$ formalin for fixation for a minimum of 2 weeks before shipment.

\section{Pathological processing and evaluation}

The detailed methodology used for pathological processing and evaluation has been published previously $[28,29]$. The McKee Laboratory evaluates brains obtained from several brain banks, including -Concussion Legacy Foundation, the Boston University-Alzheimer's Disease Center, the Framingham Heart Study, the New England Centenarian Study, the National Registry of Veterans with Amyotrophic Lateral Sclerosis, and the Veterans Administration National Posttraumatic Stress Disorder Brain Banks. Regardless of individuals' brain bank membership, all brains are processed identically and assigned a random identification number that does not identify the brain bank to which they belong. Briefly, for fresh tissue, quality control measures are followed, including RNA integrity number (Agilent Technologies, Santa Clara, CA, USA) and pH. The brain is hemisected, then one half is sectioned and frozen and the other half is fixed for 3 weeks. The fixed tissue is dissected and processed into tissue sections, including paraffin-embedded tissue sections and large, fixed coronal slabs. Tissue blocks and stains are detailed in Table 2. If screening regions are positive for $\beta$-amyloid, $\alpha$-synuclein, or phosphorylated transactive response DNA binding protein $43 \mathrm{kDa}$ (pTDP-43), additional regions are stained to allow for complete staging of these pathologies. Positive and 


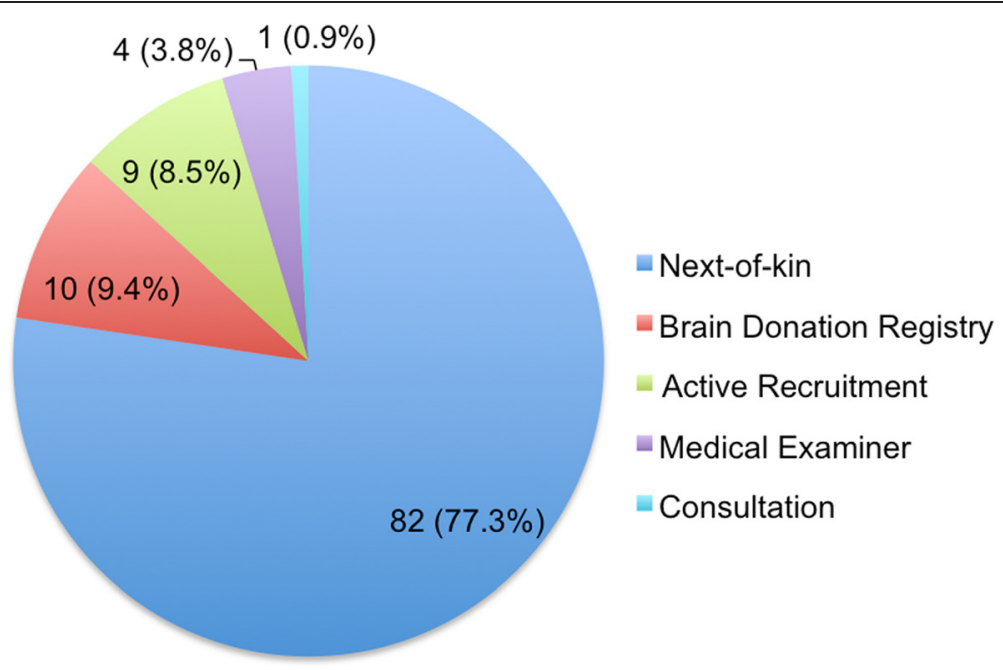

Fig. 2 Recruitment mechanisms in place at the U.S. Department of Veterans Affairs-Boston University-Concussion Legacy Foundation Brain Donation Registry and Brain Bank since Understanding Neurologic Injury and Traumatic Encephalopathy project recruitment began. Next-of-kin recruitment: A potential donor's legal next of kin contacts the brain bank near the time of death to ask about participation. Active recruitment: A member of the brain bank staff contacts a potential donor's next of kin near the time of death to ask about participation. Brain Donation Registry: A potential donor contacts the brain bank and pledges to donate upon death. Medical examiner: A medical examiner contacts the brain bank upon suspicion of a diagnosis of chronic traumatic encephalopathy or if an individual's family member expresses to the medical examiner interest in brain donation. Consultations: A neuropathologist contacts the brain bank to release tissue for further evaluation

Table 1 Inclusion and exclusion criteria for the UNITE study

\section{Descriptions}

Inclusion criteria

1. Men who played American football or ice hockey at the professional or Olympic level or who played at the collegiate, semiprofessional, or junior level for at least 2 years

2. Men who played a high-risk contact sport, other than American football or ice hockey, at the professional or Olympic level

3. Women who played a high-risk contact sport at the professional, Olympic, or collegiate level

4. Men or women who played a high-risk contact sport at the professional, Olympic, collegiate, or high school level who died before the age of 35 years

5. Men or women who played a high-risk contact sport at the professional, Olympic, collegiate, or high school level who were diagnosed with ALS during life

6. Men or women with a military history of combat exposure

7. Women with a history of domestic abuse

Exclusion criteria

1. Specimen with a postmortem interval before fixation of longer than $72 \mathrm{~h}$

2. Specimen that was embalmed following brain autopsy

3. Specimen of less than one full hemisphere

ALS, Amyotrophic lateral sclerosis; UNITE, Understanding Neurologic Injury and Traumatic Encephalopathy negative controls are stained simultaneously to identify improperly stained material.

The pathological evaluation and diagnosis occur without any knowledge of the subject's RHI or clinical history and are confirmed by two neuropathologists (ACM, TDS). Semiquantitative measures of phosphorylated tau burden (by AT8 immunostaining), $\beta$-amyloid deposition (by 4G8 immunostaining for Thal phase and Bielschowsky silver stain for Consortium to Establish a Registry for Alzheimer's Disease score), $\alpha$-synuclein-positive Lewy body and neurite burden, pTDP-43 burden, vascular disease, and neuronal loss are recorded for prespecified regions. The validated criteria for diagnosis ([2, 27], A.C. McKee) and stages [2] of CTE are summarized in Tables 3 and 4. Well-established pathological criteria are used for diagnosis of all comorbid diseases, including ALS [30, 31], AD [32-37], Parkinson's disease and Lewy body disease [38-40], FTLD (including progressive supranuclear palsy, corticobasal degeneration, and Pick's disease) [41-45], and multiple system atrophy [43]. A neuropathology report is generated that includes a description of the macroscopic and microscopic findings and a list of pathological diagnoses, including CTE stage.

\section{Retrospective clinical evaluation}

The goal of the retrospective clinical evaluation is to obtain each subject's demographic information; RHI exposure; substance use; and medical, social, and family 
Table 2 Brain tissue blocks and stains used for neuropathology

\begin{tabular}{|c|c|c|c|c|c|c|c|c|c|}
\hline \multirow[b]{2}{*}{ Brain region } & \multirow[b]{2}{*}{$\begin{array}{l}\text { Paraffin } \\
\text { blocks, } n\end{array}$} & \multicolumn{7}{|l|}{ Stain } & \multirow[b]{2}{*}{$\begin{array}{l}\text { Minimum } \\
\text { staining }^{b}\end{array}$} \\
\hline & & Reserve & $\begin{array}{l}\text { Luxol fast } \\
\text { blue }\end{array}$ & $\begin{array}{l}\text { Bielschowsky } \\
\text { silver stain }\end{array}$ & AT8 & $\begin{array}{l}\text { Amyloid- } \beta \\
(4 \mathrm{G} 8)^{\mathrm{a}}\end{array}$ & a-Synuclein $^{a}$ & $\mathrm{pTDP}-43^{\mathrm{a}}$ & \\
\hline Olfactory bulb & 1 & & $x$ & & $x$ & & $x$ & & $x$ \\
\hline Midbrain at level of red nucleus & 1 & & $x$ & & $x$ & $x$ & $x$ & $x$ & \\
\hline Midbrain at superior cerebellar peduncle & 1 & $x$ & & & & & & & \\
\hline Precentral, postcentral cortices (BA 4, 3, 2, 1) & 1 & & $x$ & & $x$ & & & & \\
\hline Inferior parietal cortex (BA 39, 40) & 1 & & $x$ & $x$ & $x$ & $x$ & & & $x$ \\
\hline Anterior cingulate (BA 24) & 1 & & $x$ & & & & $x$ & & \\
\hline Superior frontal (BA 8, 9) & 1 & & $x$ & & $x$ & & & & $x$ \\
\hline Inferior frontal cortex (BA 10, 11, 12) & 2 & & $x$ & & $x$ & & & & $x$ \\
\hline Dorsolateral frontal (BA 45, 46) & 2 & & $x$ & $x$ & $x$ & $x$ & & $x$ & $x$ \\
\hline Caudate-putamen-accumbens, septal cortex & 2 & & $x$ & & $x$ & $x$ & & & \\
\hline Insular cortex & 2 & & $x$ & & $x$ & & & & \\
\hline Temporal pole (BA 38) & 1 & & $x$ & & $x$ & & & & $x$ \\
\hline Superior temporal (BA 20, 21, 22) & 1 & & $x$ & & $x$ & $x$ & & & $x$ \\
\hline Amygdala, with entorhinal cortex (BA 28) & 1 & & $x$ & & $x$ & $x$ & $x$ & $x$ & $x$ \\
\hline Globus pallidus, insula, substantia innominata & 1 & & $x$ & & $x$ & & & & \\
\hline Anterior hippocampus & 1 & $x$ & & & & & & & \\
\hline Hippocampal formation, lateral geniculate & 1 & & $x$ & $x$ & $x$ & $x$ & & $x$ & $x$ \\
\hline Superior temporal posterior (BA 41, 42) & 1 & $x$ & & & & & & & \\
\hline Thalamus with subthalamic nucleus & 1 & $x$ & & & & & & & \\
\hline Hypothalamus, mammillary body & 1 & & $x$ & & $x$ & & & & \\
\hline Posterior thalamus & 1 & $x$ & & & & & & & \\
\hline Posterior cingulate (BA 23, 31) & 1 & $x$ & & & & & & & \\
\hline Calcarine cortex (BA 17, 18) & 1 & & $x$ & $x$ & $x$ & & & & \\
\hline Superior parietal cortex (BA 7B) & 1 & $x$ & & & & & & & \\
\hline Upper pons (level of locus coeruleus) & 1 & & $x$ & & $x$ & & & & $x$ \\
\hline Pons, middle cerebellar peduncle & 1 & $x$ & & & & & & & \\
\hline Medulla oblongata with inferior olives & 1 & & $x$ & & $x$ & & $x$ & & $x$ \\
\hline Cervical spinal cord & 1 & & $x$ & & $x$ & & & $x$ & \\
\hline Thoracic spinal cord & 1 & $x$ & & & & & & & \\
\hline Lumbar spinal cord & 1 & & $x$ & & & & & & \\
\hline Sacral spinal cord & 1 & $x$ & & & & & & & \\
\hline Cerebellar vermis & 1 & & $x$ & & $x$ & & & & \\
\hline Cerebellum with dentate nucleus & 1 & & $x$ & $x$ & $x$ & $x$ & & & $x$ \\
\hline Parastriate cortex & 1 & $x$ & & & & & & & \\
\hline
\end{tabular}

Abbreviations: BA Brodmann area, pTDP-43 phosphorylated transactive response DNA binding protein $43 \mathrm{kDa}$

alf screening regions are positive for $\beta$-amyloid, a-synuclein, or pTDP-43, additional regions are stained to allow for complete staging of these pathologies

${ }^{\mathrm{b}}$ Minimum regions that must be evaluated to make a neuropathological chronic traumatic encephalopathy diagnosis

histories, with a particular focus on possible neurodegenerative conditions, including symptom breadth, severity, and progression. The retrospective clinical evaluation comprises a combination of online surveys and telephone calls between researchers and the family members and close friends of the subject. Data are collected through an unstructured interview with either a behavioral neurologist or a neuropsychologist and with modified (for completion retrospectively, following death, by informants) versions of standardized, validated scales (Table 5). Preference was given to scales already in use in other relevant BU studies, including studies of CTE and AD [46-49], and to scales that are included in the National Institute of Neurological Disorders and 
Table 3 Pathological criteria used for CTE diagnosis

\begin{tabular}{l} 
Descriptions \\
\hline Defining criteria \\
1. Perivascular accumulation of abnormal hyperphosphorylated tau \\
within neurons, astrocytes, and/or cell processes in the neocortex \\
2. Irregular distribution of p-tau-immunoreactive cells and processes \\
at the depths of cerebral sulci \\
Supportive criteria \\
3. Macroscopic abnormalities in the septum pellucidum (cavum, \\
fenestration), disproportionate dilation of the third ventricle or \\
signs of previous brain injury \\
Abnormal tau-immunoreactive neuronal lesions affecting the \\
neocortex predominantly in superficial layers 2 and 3, as opposed \\
to layers 3 and 5 as in AD
\end{tabular}

Abbreviations: AD Alzheimer's disease, CTE chronic traumatic encephalopathy These criteria are based on previous publications [2, 27] and A.C. McKee

Stroke (NINDS) Common Data Elements. Researchers conducting these evaluations are completely blinded to the pathological examinations and findings.

There are five parts to the clinical evaluation: two online surveys (termed Online Surveys A and B), two telephone interviews (termed Clinical Interviews $\mathrm{A}$ and $\mathrm{B}$ ), and a medical record review. Informants may complete the online surveys individually or as a group (i.e., several members of the decedent's family responding together). For the clinical interviews, informants participate as a group. A behavioral neurologist or neuropsychologist (termed the lead clinician) conducts Clinical Interview A, and a research assistant conducts Clinical Interview B. To assess informant reliability, informants answer questions pertaining to the nature and duration of their relationship with the subject and the frequency with which they were in contact with the subject. A description of each part of the clinical evaluation (presented in the order in which the data are collected) is provided in the subsections below.

Table 4 CTE pathological stages

\begin{tabular}{ll}
\hline Stages & Descriptions \\
\hline 1 & $\begin{array}{l}\text { Discrete perivascular p-tau foci in the neocortex, usually found } \\
\text { at the depths of sulci }\end{array}$ \\
& $\begin{array}{l}\text { Multiple perivascular p-tau foci in the neocortex, typically at the } \\
\text { depths of the cerebral sulci, with involvement of superficial } \\
\text { layers of adjacent cortex and sparing of the medial temporal } \\
\text { lobe structures }\end{array}$ \\
& $\begin{array}{l}\text { Widespread p-tau lesions in the frontal, temporal, parietal, } \\
\text { insular, and septal neocortices, most severe at the depths of } \\
\text { the sulci and in the superficial cortical layers, with involvement } \\
\text { of the entorhinal cortex, amygdala, and hippocampus } \\
\text { Diffuse pathology throughout the cerebral cortex and the } \\
\text { medial temporal structures, sparing the calcarine cortex }\end{array}$
\end{tabular}

Abbreviation: CTE chronic traumatic encephalopathy, $p$-tau phosphorylated tau CTE pathological stages are based on extent and anatomic distribution of p-tau pathology [2]
Table 5 Administered clinical scales

\begin{tabular}{ll}
\hline Scales & $\begin{array}{l}\text { Clinical evaluation } \\
\text { sections }\end{array}$ \\
\hline $\begin{array}{l}\text { Ohio State University TBI Identification Method } \\
\text { Short Form [50] }\end{array}$ & Clinical Interview A \\
Geriatric Depression Scale [51] & Online Survey B \\
Cognitive Difficulties Scale [52] & \\
Behavioral Rating Inventory of Executive & \\
Function-Adult Version [53] & \\
BIS-11 [54] & \\
Apathy Evaluation Scale [55] & \\
ALS Functional Rating Scale ${ }^{\mathrm{a}}[56]$ &
\end{tabular}

Functional Assessment Questionnaire [57]

Clinical Interview B

Clinician Assessment of Fluctuations [58]

Brown-Goodwin Aggression Scale [59]

Structured Clinical Interview for DSM-IV [60]

Abbreviations: ALS Amyotrophic lateral sclerosis; DSM-IV Diagnostic and Statistical Manual of Mental Disorders, Fourth Edition, TBI Traumatic brain injury

All scales were adapted to account for data being collected retrospectively from an informant

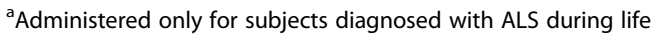

\section{Online Survey $A$}

Online Survey A queries the subject's demographic information, educational attainment, occupational history, living situation before death, athletic history (type of sports played, level, position, age of first exposure, and duration), and military history (branch, location of service, and duration of combat exposure). The survey uses a nested question structure with skip logic to ensure that questions are appropriately tailored to each subject.

\section{Clinical Interview A}

During Clinical Interview A, the clinician (a behavioral neurologist or a neuropsychologist) obtains a detailed medical history, including traumatic brain injuries (TBIs), and recreates a timeline of cognitive, behavioral, and mood symptomatology. Specifically, the clinician asks semistructured questions about cause of death, medical history (including vascular risk factors), neurological history (including risk factors for cognitive and motor impairment), and psychiatric history. The clinician then asks semistructured questions about mild to severe TBIs using the Ohio State University TBI Identification Method Short Form [50] and two questionnaires, adapted from published studies, that address military-related head injuries and concussions that result in even the mildest symptoms $[47,48]$. Finally, using unstructured questions, the clinician obtains a precise chronology of deficits in cognition (memory, executive function, attention/concentration, language, visuospatial function), behavior and/or mood (depression, apathy, mania, anxiety, irritability/anger, abusiveness, social inappropriateness, psychosis), and daily function (including instrumental activities of daily living). 
Motor functioning, sleep, headaches, substance use, and family history are queried in the same manner. Once the interview is completed, the clinician answers several summary questions about predominant symptoms (cognitive, mood, behavior, motor), symptom onset, and disease progression.

\section{Online Survey $B$}

Online Survey B is used to collect data about the subject's cognition, mood, and behavior (including impulsivity and apathy) through the administration of the following validated scales: Geriatric Depression Scale Short Form [51], Cognitive Difficulties Scale (CDS) [52], Behavior Rating Inventory of Executive Function-Adult Version [53], Barratt Impulsivity Scale version 11 (BIS-11) [54], and Apathy Evaluation Scale (AES) [55]. For subjects diagnosed during life with ALS, the ALS Functional Rating Scale [56] is also administered.

\section{Clinical Interview B}

In Clinical Interview $B$, the researcher asks informants semistructured questions to quantify information obtained qualitatively in Clinical Interview A. Some questions from Online Survey B are repeated for quality control. Specifically, family history is obtained using modified questions from the National Alzheimer's Coordinating Center Uniform Data Set [49]. Cognitive functioning, including memory, language, attention, executive function, and visuospatial function, is assessed using selected questions from the informant section of the CDS [52]. Daily function, cognitive fluctuations, and aggression are assessed using the Functional Assessment Questionnaire [57], the Clinician Assessment of Fluctuations [58], and the BrownGoodwin Aggression Scale [59], respectively. Impulsivity and apathy are assessed using selected questions from the BIS-11 [54] and the AES [55], respectively. The presence of major depressive disorder, bipolar disorder, anxiety disorders (including panic disorder, obsessive compulsive disorder, agoraphobia, social anxiety disorder, specific phobias, generalized anxiety disorder, and posttraumatic stress disorder), psychosis, substance use, and somatoform disorders is assessed using modified questions from the Structured Clinical Interview for DSM-IV [60]. Sleep and headache are briefly assessed using modified questions from the Mayo Sleep Questionnaire [61] and the Cleveland Clinic Headache Intake Questionnaire, respectively [62]. Motor function is assessed using questions developed internally to query symptoms of parkinsonism.

\section{Medical record review}

For all incoming cases, we request permission from the subject's legal next of kin or LAR to review medical records as well as the names and locations of health care providers. A research assistant contacts the health care providers to request the records, including original brain imaging (rather than just a report). The research assistant initially reviews all records and extracts salient information, including psychiatric, neurological, and neuropsychological evaluations; brain imaging; medical history; and medications. A behavioral neurologist and a neuropsychologist then review the extracted information, including original images if available. Information gathered during the medical record review is combined with the data gathered in the previous steps to complete the clinical evaluation.

\section{Clinicopathological consensus conference}

Clinical consensus methodology is based on recommendations of Bertens et al. [63]. At a twice-monthly clinicopathological consensus conference (CPC), a panel of doctoral-level clinicians reaches a clinical consensus diagnosis using clinical research criteria [38, 61, 64-69], including those recently proposed for CTE [5] (Fig. 3). The clinical panel is composed of neuropsychologists, neurologists, psychiatrists, and neurosurgeons who specialize in neurodegenerative disease and/or TBI. At least three and upward of six panel members are present for each CPC.

For each case, a lead clinician reads a standardized clinical summary based on the information collected during the retrospective clinical evaluation. This summary outlines the disease course. It also includes age at death and cause of death; a subjective assessment of informant reliability; prior athletic, military, and TBI history; past medical, educational, and occupational history; living situation before death; substance use history; and family history. Last, it includes salient features in medical records, including neuropsychological testing, neuroimaging (including a reading from a behavioral neurologist if original images are available), CSF biomarkers, diagnoses made during life, and medications prescribed. At the conclusion of the clinical presentation and before any formal discussion, each clinical consensus member votes independently, without discussion, on whether criteria for traumatic encephalopathy syndrome (TES) [5] are met. The diagnosis of TES, which incorporates CTE, is made on the basis of criteria outlined by Montenigro et al. [5], with modification because neuropsychological testing may not have been conducted during the subject's life. Although several groups have proposed CTE clinical criteria [7, 8], use of the Montenigro et al. criteria provides several advantages. To be included in the core criteria, signs and symptoms needed to be frequent (70\%) among cases diagnosed neuropathologically with CTE using the criteria proposed by McKee et al. [2] and free of comorbid neurodegenerative disease. The criteria also are operationalized for research, explicitly defining the 


\begin{tabular}{|c|c|c|}
\hline \multicolumn{3}{|c|}{ A. General criteria for TES (all 4 criteria must be met for diagnosis) } \\
\hline \multicolumn{3}{|c|}{ i) At least 4 concussions or mild TBIs } \\
\hline \multicolumn{3}{|c|}{ ii) At least 2 moderate/severe TBls } \\
\hline \multicolumn{3}{|c|}{ iii) At least 6 years of organized contact sports } \\
\hline \multicolumn{3}{|c|}{ iv) Military service with combat exposure } \\
\hline \multicolumn{3}{|c|}{ v) Other significant RHI (e.g. domestic abuse) } \\
\hline \multicolumn{3}{|c|}{ 2. "Core clinical features" (at least 1 must be present) } \\
\hline \multicolumn{3}{|c|}{$\begin{array}{l}\text { Cognitive. Significant impairment in memory, orientation, language, attention, } \\
\text { executive function or visuospatial function }\end{array}$} \\
\hline \multicolumn{3}{|c|}{$\begin{array}{l}\text { Behavioral. Described as explosive, short fuse, out of control, physically and/or } \\
\text { verbally violent. Or intermittent explosive disorder }\end{array}$} \\
\hline \multicolumn{3}{|c|}{$\begin{array}{l}\text { Mood. Feeling overly sad, depressed, or hopeless. Or diagnosis of major depressive } \\
\text { disorder or persistent depressive disorder }\end{array}$} \\
\hline \multicolumn{3}{|c|}{ 3. "Supportive features" (at least 2 must be present) } \\
\hline \multicolumn{3}{|c|}{$\begin{array}{l}\text { Documented decline (at least } 1 \text { year), delayed symptom onset after exposure, } \\
\text { impulsivity, anxiety, apathy, paranoia, suicidality, headache, motor impairment }\end{array}$} \\
\hline \multicolumn{3}{|c|}{ 4. Clinical features must be present for a minimum of 12 months } \\
\hline \multirow{2}{*}{\multicolumn{3}{|c|}{$\begin{array}{l}\text { B. Criteria for TES diagnostic subtypes and modifiers } \\
\text { Diaanostic subtvpes ( select onlv } 1 \text { ) }\end{array}$}} \\
\hline & & \\
\hline 'Cognitive' & \multicolumn{2}{|c|}{$\begin{array}{l}\text { Cognitive core features are present without behavioral or mood core } \\
\text { features and without functional impairment }\end{array}$} \\
\hline $\begin{array}{l}\text { 'Behavioral/ } \\
\text { Mood' }\end{array}$ & \multicolumn{2}{|c|}{$\begin{array}{l}\text { Behavioral and/or mood core features are present without cognitive } \\
\text { core features }\end{array}$} \\
\hline 'Mixed' & \multicolumn{2}{|c|}{$\begin{array}{l}\text { Both cognitive and behavioral/mood core features are present, but } \\
\text { without functional impairment }\end{array}$} \\
\hline 'Dementia' & \multicolumn{2}{|c|}{ Cognitive core features and functional impairment are present } \\
\hline \multicolumn{3}{|c|}{ "With motor features" modifier (at least 1 must be present) } \\
\hline \multicolumn{3}{|c|}{$\begin{array}{l}\text { Dysarthria, dysgraphia, bradykinesia, tremor, rigidity, gait change, falls, and/or other } \\
\text { features of parkinsonism }\end{array}$} \\
\hline \multicolumn{3}{|c|}{ Clinical course modifier (select only 1 ) } \\
\hline 'Stable' & \multicolumn{2}{|c|}{ History or tests indicate little if any change } \\
\hline 'Progressive' & \multicolumn{2}{|c|}{ Clear indication of progression over 2 years } \\
\hline \multicolumn{3}{|c|}{ 'Unknown/inconsistent' $\quad$ Unknown or inconsistent information } \\
\hline C. Chronic Traur & Iatic Encephalopa & y (CTE) likelihood criteria (select only 1) \\
\hline & Progressive cour & \\
\hline & & Positive PET tau imaging \\
\hline & & Negative PET amyloid imaging \\
\hline & & Normal beta amyloid CSF levels \\
\hline & & Elevated CSF p-tau/tau ratio \\
\hline $\begin{array}{l}\text { (must meet all } \\
\text { criteria) }\end{array}$ & $\begin{array}{l}\text { be present } \\
\text { be }\end{array}$ & Cavum septum pellucidum on an imaging study \\
\hline & & Cortical thinning or atrophy on an imaging study \\
\hline & If PET tau imagin & was performed, it must be positive \\
\hline & $\begin{array}{l}\text { Another neurolog } \\
\text { features and bion }\end{array}$ & $\begin{array}{l}\text { cal disorder does not better account for the clinical } \\
\text { larkers }\end{array}$ \\
\hline 'Possible CTE' & Does not meet $\mathrm{cr}$ & teria for Probable CTE \\
\hline (must meet all & & \\
\hline criteria) & If PET tau imagin & was performed, it must be positive \\
\hline 'Unlikely CTE' & Does not meet $\mathrm{cr}$ & teria for probable or possible CTE \\
\hline
\end{tabular}

Fig. 3 Adapted clinical diagnostic criteria for traumatic encephalopathy syndrome ${ }^{a}$. Abbreviations: CSF cerebrospinal fluid, CTE chronic traumatic encephalopathy, PET positron emission tomography, p-tau phosphorylated tau, RHI repetitive head injuries, TBI traumatic brain injury, TES traumatic encephalopathy syndrome. ${ }^{a}$ Criteria adapted from Montenigro et al. [5]

minimum required exposure level, supportive features, subtype designations, potential biomarkers, and relative likelihood of CTE (probable, possible, or unlikely). Of note, TES is a broad umbrella term meant to describe the clinical presentation of CTE as well as other possible long-term consequences of RHI, including other neurodegenerative diseases. A TES diagnosis neither necessitates a possible or probable CTE diagnosis nor excludes another clinical neurodegenerative diagnosis [5].

If the criteria for TES are met, the clinician indicates the subtype designations and the relative likelihood of 
underlying CTE (probable, possible, or unlikely) based upon additional supportive features [5]. The clinicians also record a primary clinical diagnosis and, if appropriate, contributing clinical diagnoses. Figure 4 shows the diagnostic form that each clinician completes. After each clinician, blinded to the other clinicians' diagnoses, completes and submits the diagnostic form, the group discusses the case. The discussion includes questioning of the lead clinician about specific details with the goal of reaching a consensus diagnosis using a format identical to that used for the previous independent voting. To reach consensus, a majority of the clinicians present must agree on the diagnosis. Once a consensus diagnosis is reached, panel members again complete a written diagnostic form as a means to record dissent from the consensus.

After the clinicians reach a consensus, the neuropathologist who evaluated the case presents the pathological findings. The presentation includes the brain weight, gross and microscopic images, and an overall summary. The presentation focuses on 1) regional patterns of cerebral and white matter atrophy, 2) evidence of septal abnormalities, including cavum septum pellucidum or fenestrations, 3) pallor of the substantia nigra and locus coeruleus, 4) extent and anatomic distribution of neuronal loss and gliosis, 5) immunohistochemistry ( $\mathrm{p}$-tau, $\beta$-amyloid, pTDP-43 and $\alpha$-synuclein) and 6) vascular pathology. The summary includes pathological diagnoses with staging when appropriate. All neuropathological diagnoses and associated reports are completed before the consensus conference and without knowledge of the subject's antemortem exposure history or clinical presentation, and they are not changed on the basis of clinicians' diagnoses or discussions.

After the clinical and pathological presentations, the clinicians and pathologists discuss clinicopathological correlation. For each case, the physicians and neuropsychologists identify key summary features of the case that help inform future research directions. For cases with discrepancies between the clinical and pathological findings, the cause of the differences and how the discrepancies contribute to diagnostic uncertainty are discussed.

Last, the lead clinician and pathologist present both the clinical and pathological diagnoses to the informants by telephone. The informants are also provided with a written report that summarizes the diagnoses.

\begin{tabular}{|c|c|c|c|c|c|c|}
\hline \multirow[t]{2}{*}{ If TES yes: } & Subtype: & CTE & Course & \multicolumn{2}{|c|}{$\begin{array}{c}\text { Motor } \\
\text { (Parkinsonism) }\end{array}$} & $\begin{array}{l}\text { Motor Neuron } \\
\text { Disease }\end{array}$ \\
\hline & $\begin{array}{l}\text { TES cognitive } \\
\text { TES behavioral } \\
\text { TES mixed } \\
\text { TES dementia } \\
\text { TES }\end{array}$ & $\begin{array}{l}\text { Probable } \\
\square \text { Possible } \\
\square \text { Unlikely }\end{array}$ & $\begin{array}{l}\text { QStable } \\
\text { QProgressive } \\
\text { OUnknown/ } \\
\text { inconclusive }\end{array}$ & $\begin{array}{l}\text { पYyes } \\
\square \text { No }\end{array}$ & & $\begin{array}{l}\text { QYes } \\
\text { पNo }\end{array}$ \\
\hline \multicolumn{4}{|c|}{ Diagnosis: } & & Primary & Contributing \\
\hline \multicolumn{5}{|c|}{ 1. CTE (Only choose if TES is present) } & & \\
\hline \multicolumn{5}{|c|}{ Residual problems after mild TBI - post-concussive syndrome - distinct from CTE } & & \\
\hline \multirow{2}{*}{\multicolumn{7}{|c|}{ 3. Residual problems after moderate to severe TBI - distinct from CTE }} \\
\hline \multicolumn{3}{|c|}{ Pre-Alzheimer's dementia } & & & & \\
\hline \multicolumn{7}{|c|}{ 5. Alzheimer's dementia } \\
\hline \multicolumn{7}{|c|}{ Dementia with Lewy bodies } \\
\hline \multicolumn{7}{|c|}{ 7. Vascular burden (Pre-vascular dementia) } \\
\hline \multicolumn{7}{|c|}{ 8. $\quad$ Vascular dementia } \\
\hline \multirow{2}{*}{\multicolumn{7}{|c|}{$\begin{array}{ll}\text { 9. } & \text { Behavioral variant - frontotemporal dementia } \\
\text { 10. } & \text { Primary progressive aphasia (specify: } \square \text { semantic } \square \text { non-fluent } \square \text { logopenic) }\end{array}$}} \\
\hline & & & & & & \\
\hline \multicolumn{7}{|c|}{ 11. ALS/motor neuron disease - associated with CTE } \\
\hline \multicolumn{7}{|c|}{ 12. ALS/motor neuron disease - not associated with CTE } \\
\hline \multicolumn{7}{|c|}{ 13. FTD/ALS - not associated with CTE } \\
\hline \multicolumn{7}{|c|}{ 14. Depression } \\
\hline \multicolumn{7}{|c|}{ 15. Bipolar disorder } \\
\hline \multicolumn{7}{|c|}{ 16. Post-traumatic stress disorder } \\
\hline \multirow{2}{*}{\multicolumn{7}{|c|}{ 17. Anxiety disorder (Please specify:_ }} \\
\hline $\begin{array}{l}\text { 17. Anxiety disorder (Please specify:___ } \\
\text { 18. Schizophrenia }\end{array}$ & & & & & & \\
\hline \multicolumn{7}{|c|}{ 19. Intermittent Explosive Disorder } \\
\hline 20. Other major psychiat & ic illness: & & & & & \\
\hline 21. Impairment due to su & stance abuse (alcoho & , prescriptio & or illicit) & & & \\
\hline 22. Alcohol-related deme & & & & & & \\
\hline 23. Parkinson's disease & specify: $\square$ without d & mentia $\square w$ & d dementia) & & & \\
\hline 24. Progressive supranuc & ear palsy & & & & & \\
\hline 25. Corticobasal degener & & & & & & \\
\hline 26. Huntington's disease & & & & & & \\
\hline 27. Normal pressure hyd & ocephalus & & & & & \\
\hline 28. Prion disease & & & & & & \\
\hline 29. Paraneoplastic syndr & & & & & & \\
\hline 30. Stroke (without cogni & ive impairment) & & & & & \\
\hline 31. CNS neoplasm & & & & & & \\
\hline 32. Epilepsy & & & & & & \\
\hline 33. Multiple Sclerosis & & & & & & \\
\hline 34. Impairment from mes & ical illness & & & & & \\
\hline 35. Iatrogenic impairmen & & & & & & \\
\hline 36. Other: & & & & & & \\
\hline & & & & & & \\
\hline
\end{tabular}

Fig. 4 Clinical consensus diagnostic form completed by each clinician. ALS amyotrophic lateral sclerosis, CNS central nervous system, CTE chronic traumatic encephalopathy, FTD frontotemporal degeneration, TBI traumatic brain injury, TES traumatic encephalopathy syndrome 


\section{Data analysis}

The data analysis will involve three major phases. Phase 1 will evaluate the reliability of the consensus raters and the validity of the clinical research criteria for CTE and the consensus process $[63,70]$. For our primary analyses, we will consider a dichotomous clinical diagnosis (i.e., possible or probable CTE vs. no CTE). First, we will calculate the pre- and postconsensus interrater reliability (Cohen's $\mathrm{\kappa}$ ) between clinical consensus members $[63,70,71]$, along with the standard errors and $95 \%$ confidence intervals. Next, we will calculate the pre- and postconsensus sensitivity, specificity, and accuracy of the clinical diagnosis using the presence of CTE pathology as a gold standard. In secondary analyses, we will assess the reliability and validity of clinical subtypes and an alternative operationalization of the likelihood of CTE (i.e., probable CTE vs. possible or no CTE).

Phase 2 of the analysis involves an evaluation of sources of diagnostic disagreement between clinical consensus members and sources of diagnostic error between the consensus diagnosis and the pathological diagnosis. For each case with diagnostic disagreement (either preor postconsensus), we will review the case and identify the issues leading to the disagreement. We will review how these major issues differ pre- and postconsensus, paying particular attention to those that remain or that occur postconsensus. Similarly, for each case with a consensus diagnostic error, we will review the case and identify the major issue leading to the error. We will calculate the frequency of each type of diagnostic error (e.g., frequency of clinical consensus diagnosis of CTE with pathological AD). Finally, we will review differences in diagnostic errors between false positives and false negatives.

Phase 3 involves the analysis of individual diagnostic features (examples include but are not limited to contact sport position, years and level of play, number and severity of individual TBIs, memory impairment, depression, impulsivity, and motor impairment). We will calculate the sensitivity and specificity of each feature using pathological CTE as a gold standard. Among cases of pathological CTE, we will calculate the frequency of each feature overall, as the presenting symptom and/or sign, as an early symptom and/or sign, and as a late symptom and/or sign. Next, we will create statistical models of pathological CTE risk, using these diagnostic features as predictors. We will use conventional logistic regression as well as two machine learning algorithms: random forests and elastic net penalized logistic regression. The machine learning algorithms account for the often erroneous assumptions of classical logistic regression that predictors are not correlated with each other and that their effects are additive [72]. Diagnostic features with the best sensitivity and specificity, and that best predict CTE pathology, will be critical to include in future iterations of clinical diagnostic criteria for CTE.

\section{Discussion}

The last decade has seen an increased interest in understanding the relationship between RHI and the development of neurodegenerative disorders, most centrally CTE. As CTE is closely linked to participation in contact sports such as American football and to head injuries sustained by soldiers participating in the conflicts in Iraq and Afghanistan, the topic also has garnered considerable attention from the media and the public at large. Recently, the NIH, the National Football League (NFL), and the U.S. Department of Defense sponsored further research to elucidate the connection between RHI and the development of CTE [73-75]. The UNITE study is part of this initiative. Here, we describe the UNITE study methodology for examining clinicopathological correlation in CTE.

The UNITE methodology has several strengths, including extensive and carefully designed data collection and the use of best practices to reach a clinical consensus diagnosis [63]. Retrospective clinical data collection from informants includes an unstructured interview, a structured interview, two online surveys, and a review of medical records. In the unstructured interview, an experienced behavioral neurologist or neuropsychologist obtains a comprehensive disease timeline, similarly to an initial clinical visit, so that the case can be presented in detail at a consensus conference. Via the structured interview and online surveys, data are collected that can be coded and analyzed to answer questions about signs and symptoms of disease, independently of the consensus diagnosis. Pathological data collection includes exhaustive sampling of brain regions and comprehensive immunohistochemical analysis. All vascular and neurodegenerative pathological diagnoses are made on the basis of recently validated CTE criteria ([2, 27], A.C. McKee) or other well-established criteria.

In designing our methodology for reaching a clinical consensus diagnosis, we followed best practices, paying careful attention to the evaluating panel's constitution, information presented to the panel, and the diagnostic decision-making process for consensus [63, 76]. Our panelists have diverse training (behavioral neurology, neurosurgery, neuropsychology, brain injury and rehabilitation, and psychiatry) and decades of professional experience in areas germane to the study of CTE, including neurodegenerative disease and TBI. The information presented to the panel is based on methodology used in the study of $\mathrm{AD}$ [77] and consists of a written summary of the disease course and medical, social, and family histories $[1,5,7,26]$. The diagnostic decision- 
making process follows recommended procedures. Consensus members make an individual preliminary diagnosis before discussion with other panel members. Consensus diagnosis, subtype designations, and likelihood of CTE are determined by majority vote after a panel discussion. Individual dissension from the consensus diagnosis is recorded for later analysis [63].

Our study design allows not only for testing the validity of clinical research criteria and the consensus process but also for recognizing sources of error and identifying diagnostic features that best predict CTE pathology. We have proposed several approaches in the Data Analysis section above to conduct these analyses that will allow us to move past the traditional case series approach that has largely defined CTE research to date. For example, whereas there are clear pathological differences between CTE and AD, understanding and differentiating the clinical symptoms, particularly in older adults, remains a significant challenge [78]. Analyzing the cases collectively using a quantitative approach will help us better understand the clinical distinctions between these diseases. Clinical diagnostic features that best predict CTE pathology will be critical to include in future iterations of clinical diagnostic criteria for TES and CTE. In particular, as potential in vivo biomarkers for CTE are developed, the UNITE methodology will provide a critical mechanism by which to examine their predictive validity.

We strive to be methodologically rigorous, but several potential limitations need to be highlighted. In any study involving brain donation, there is clear ascertainment bias. Even though brain donors are selected on the basis of their exposure to repetitive brain trauma, families that donate are more likely to have witnessed symptoms during the donor's life [26]. Ascertainment bias increases the probability of CTE being present at autopsy and may also limit variability and increase the mean severity of clinical presentation. All of these factors in turn could affect the reliability and validity of the consensus diagnosis. To address this bias, our recruitment network actively encourages the recruitment of subjects without or with limited symptoms who were exposed to RHI. As more asymptomatic brain donors are included in the study, the generalizability of our findings will increase.

Because we ask informants to recall information from years earlier, there is potential for recall bias. Informants may recall events or symptoms more clearly if they occurred closer to the time of death or if they strongly affected the informant. Further, if the informants did not witness events, they may be unaware or poorly informed of what occurred. This is especially common for subjects' children who may not have been living or who were very young when RHI occurred. We have tried to reduce recall bias by making our structured interview comprehensive so that informants must only recognize that symptoms were present rather than need to freely recall that they occurred. We also pay special attention to the age at individual symptom onset.

Because we do not evaluate subjects during their lives, the lead clinician cannot present firsthand observations of the subject and standardized, objective data, including neuropsychological and biomarker data, cannot be collected. The lack of these data introduces error into the clinical diagnoses. Although we carefully review medical records, including clinicians' impressions and neuropsychological, imaging, and CSF data, the medical record data we collect are neither universal nor uniform. Further, there may be discrepancies between the data collected from informants and medical record data. Because the structured data collection is standardized and these data are present for all subjects, we plan to use these data alone for our item-level analyses. However, for the consensus diagnosis, we consider all data-structured, unstructured, and from the medical record review. It is up to the lead clinician to present a cogent history to the consensus group, acknowledging to the group any discrepancies in the data.

Clinicopathological studies are not designed to assess causality. To assess whether trauma is a cause of CTE in a human study would require precise longitudinal monitoring of brain trauma exposure and a method to detect and monitor the presence of CTE during life, neither of which is currently possible. Numerous case reports and case studies have strongly suggested a direct association between RHI and the development CTE $[2,10-12,15,26,79]$, and all cases of pathologically confirmed CTE have included a history of RHI. The goal of the UNITE study is not to establish this causal link, but rather to examine clinicopathological correlation. However, given the strong association between RHI and CTE, RHI is a central component of the UNITE inclusion criteria.

Finally, the retrospective clinicopathological approach has been used successfully to characterize neurodegenerative disease over the past century [74, 75]. In $\mathrm{AD}$, the development of clinical diagnostic criteria [64] and the retrospective validation of these criteria using consensus diagnosis and neuropathology as a gold standard [77] long preceded prospective longitudinal validation. Similar retrospective methodology also was used for other neurodegenerative diseases, including the behavioral variant of frontotemporal dementia [61].

\section{Conclusions}

In the 20 months of active study recruitment to date, our team has successfully brought 99 cases to consensus and an additional 28 brain donations are awaiting consensus evaluation. When combined with previous cases, the VA-BU-CLF brain bank currently holds 172 
pathologically confirmed cases of CTE, representing the vast majority of cases of CTE reported to date [80]. This collection of CTE cases has already led to important advances in understanding of the pathobiology of CTE $[2,12,21,81]$ and has been instrumental in the initial stages of validation of the neuropathological criteria for CTE [2]. Although beyond the scope of this article, UNITE has several additional goals, including imaging of ex vivo tissue to guide the development of CTE biomarkers, investigating neurodegenerative comorbidity in CTE, staging of CTE disease severity, modeling RHI as risk factor for CTE, and evaluating genes and gene-environment interactions as a risk factor for CTE. In coordination with NIH biobanks and the Federal Interagency Traumatic Brain Injury Research informatics system, the VA-BU-CLF brain bank and the UNITE study will be used to establish a multisite biospecimen and data repository that will make tissue and data available to qualified investigators around the world who are studying the effects of RHI. These initiatives funded by NINDS and the National Institute of Biomedical Imaging and Bioengineering also will be fundamental to understanding CTE pathogenesis, determining therapeutic research targets, and advancing the clinical diagnosis of CTE.

\section{Abbreviations}

AD: Alzheimer's disease; ADC: Alzheimer's Disease Center; AES: Apathy Evaluation Scale; ALS: Amyotrophic lateral sclerosis; BA: Brodmann area; BIS11: Barratt Impulsivity Scale version 11; BU: Boston University; CDS: Cognitive Difficulties Scale; CLF: Concussion Legacy Foundation; CPC: Clinicopathological consensus conference; CSF: Cerebrospinal fluid; CTE: Chronic traumatic encephalopathy; FTLD: Frontotemporal lobar degeneration; LAR: Legally authorized representative; NFL: National Football League; NIH: National Institutes of Health; NINDS: National Institute of Neurological Disorders and Stroke; PET: Positron emission tomography; p-tau: Hyperphosphorylated tau; pTDP-43: Phosphorylated transactive response DNA binding protein 43 kDa; RHI: Repetitive head impacts; TBI: Traumatic brain injury; TES: Traumatic encephalopathy syndrome; UNITE: Understanding Neurologic Injury and Traumatic Encephalopathy; VA: U.S. Department of Veterans Affairs.

\section{Competing interests}

CJN receives travel reimbursements from the NFL Players Association, Major League Lacrosse, World Wrestling Entertainment (WWE) and the Ivy League. He receives royalties from the publication of his book Head Games: The Global Concussion Crisis, published by Head Games The Film. He served as a consultant for MC10, Inc. (Lexington, MA, USA) as recently as 2013. He serves as executive director of the Concussion Legacy Foundation and has received speaking fees on its behalf. RCC receives compensation from the NFL as senior advisor to its Head, Neck and Spine Committee, from the National Operating Committee on Standards for Athletic Equipment as chair of its Scientific Advisory Committee, and from the Concussion Legacy Foundation as cofounder and medical director for some talks given. He receives royalties from Houghton Mifflin Harcourt (Boston, MA, USA) and compensation from expert legal opinion. RAS has received research funding from the NFL, the NFL Players Association and Avid Radiopharmaceuticals, Inc. (Philadelphia, PA, USA). He is a member of the Mackey-White Traumatic Brain Injury Committee of the NFL Players Association. He is a paid consultant to Athena Diagnostics/Quest Diagnostics (Marlborough, MA, USA), Amarantus BioScience Holdings, Inc. (San Francisco, CA, USA), and Janssen Research \& Development, LLC (Raritan, NJ, USA). He has been a consultant to Janssen Alzheimer Immunotherapy (South San Francisco, CA, USA) and Eli Lilly and Company (Indianapolis, IN, USA). He receives royalties for published neuropsychological tests from Psychological
Assessment Resources, Inc. (Lutz, FL, USA) and compensation from expert legal opinion. JM, TMS, DHD, LMu, PTK, PHM, JK, BA, BF, KJB, APB, ZP, LMC, BMA, BRM, $D D, C C, V E A, Y T, T D S, L E G, D I K, N W K$ and ACM declare that they have no competing interests.

\section{Authors' contributions}

JM and TMS conducted retrospective clinical interviews, participated in clinical consensus diagnosis and made substantial contributions to study conception and design and the drafting and critical revision of the manuscript for important intellectual content. DHD conducted retrospective clinical interviews, made substantial contributions to study conception and design and critically revised the manuscript for important intellectual content. PTK conducted retrospective clinical interviews, participated in subject recruitment and made substantial contributions to study conception and design and drafting and critical revision of the manuscript for important intellectual content. LMu participated in subject recruitment and made substantial contributions to study conception and design and drafting and critical revision of the manuscript for important intellectual content. PHM conducted retrospective clinical interviews and made substantial contributions to study conception and design and drafting and critical revision of the manuscript for important intellectual content. JK made substantial contributions to study conception and design and drafting and critical revision of the manuscript for important intellectual content. BA and ZP participated in clinical data curation and made substantial contributions to critical revision of the manuscript for important intellectual content. BF participated in subject recruitment and made substantial contributions to critical revision of the manuscript for important intellectual content. KJB and JWA participated in pathological data curation and made substantial contributions to critical revision of the manuscript for important intellectual content. APB made substantial contributions to study conception and design and critical revision of the manuscript for important intellectual content. LMc and CJN participated in subject recruitment and made substantial contributions to critical revision of the manuscript for important intellectual content. BMA, BRM, DD and CC participated in clinical and pathological data curation and made substantial contributions to critical revision of the manuscript for important intellectual content. VEA participated in pathological diagnosis and made substantial contributions to critical revision of the manuscript for important intellectual content. YT participated in statistical analysis and made substantial contributions to study conception and design and critical revision of the manuscript for important intellectual content. TDS and ACM participated in pathological diagnosis and made substantial contributions to study conception and design and drafting and critically revision of the manuscript for important intellectual content. LEG, DIK, NWK, RCC and RAS participated in clinical consensus diagnosis and made substantial contributions to conception and design and critical revision of the manuscript for important intellectual content. All authors have given final approval of the version to be published and agreed to be accountable for the work.

\section{Acknowledgments}

The authors gratefully acknowledge the use of the resources and facilities at the Edith Nourse Rogers Memorial Veterans Hospital (Bedford, MA, USA). We also gratefully acknowledge the help of all members of the Chronic Traumatic Encephalopathy Program at Boston University School of Medicine, the VA Boston Healthcare System, and the individuals and families whose participation and contributions made this work possible. This work was supported by the National Institute of Neurological Disorders and Stroke (grants 1UO1NS086659-01, R01 NS078337, R56 NS078337), the U.S. Department of Defense (grant W81XWH-13-2-0064), the U.S. Department of Veterans Affairs, the Veterans Affairs Biorepository (CSP 501), the Translational Research Center for Traumatic Brain Injury and Stress Disorders (TRACTS), the Veterans Affairs Rehabilitation Research and Development Traumatic Brain Injury Center of Excellence (grant B6796-C), the National Institute on Aging Boston University Alzheimer's Disease Center (grant P30AG13846; supplement 0572063345-5), the Department of Defense Peer Reviewed Alzheimer's Research Program (DoD-PRARP grant 13267017), the National Institute on Aging Boston University Framingham Heart Study (grant R01 AG1649), the National Operating Committee on Standards for Athletic Equipment, and the Sports Legacy Institute. This work was also supported by unrestricted gifts from the Andlinger Family Foundation, the WWE, and the NFL. 


\section{Author details}

${ }^{1}$ Alzheimer's Disease Center, Boston University School of Medicine, 72 East Concord Street, B-7800, Boston, MA 02118, USA. ²Department of Neurology, Boston University School of Medicine, 72 East Concord Street, Boston, MA 02118, USA. ${ }^{3}$ Sports Legacy Institute, 230 Second Avenue, Waltham, MA 02451, USA. ${ }^{4}$ Department of Anatomy and Neurobiology, Boston University School of Medicine, 72 East Concord Street, Boston, MA 02118, USA. ${ }^{5}$ Data Coordinating Center, Boston University School of Public Health, 715 Albany

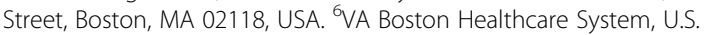
Department of Veterans Affairs, 150 South Huntington Street, Jamaica Plain, MA 02130, USA. Department of Veterans Affairs Medical Center, 200 Springs Road, Bedford, MA 01730, USA. ${ }^{8}$ Department of Pathology, Boston University School of Medicine, 72 East Concord Street, Boston, MA 02118, USA. ${ }^{9}$ Department of Biostatistics, Boston University School of Public Health, 72 East Concord Street, Boston, MA 02118, USA. ${ }^{10}$ Braintree Rehabilitation Hospital, 250 Pond Street, Braintree, MA 02184, USA. ${ }^{11}$ Department of Pathology and Laboratory Medicine, Boston University School of Medicine, 72 East Concord Street, Boston, MA 02118, USA. ${ }^{12}$ Department of Neurosurgery, Boston University School of Medicine, 72 East Concord Street, Boston, MA 02118, USA. ${ }^{13}$ Department of Neurosurgery, Emerson Hospital, 133 Old Road to Nine Acre Corner, Concord, MA 01742, USA.

\section{Received: 3 July 2015 Accepted: 15 September 2015}

\section{Published online: 12 October 2015}

\section{References}

1. Stern RA, Riley DO, Daneshvar DH, Nowinski CJ, Cantu RC, McKee AC. Long-term consequences of repetitive brain trauma: chronic traumatic encephalopathy. PM R. 2011;3:S460-7.

2. McKee AC, Stern RA, Nowinski CJ, Stein TD, Alvarez VE, Daneshvar DH, et al. The spectrum of disease in chronic traumatic encephalopathy. Brain. 2013;136:43-64. doi:10.1093/brain/aws307.

3. Mez J, Stern RA, McKee AC. Chronic traumatic encephalopathy: where are we and where are we going? Curr Neurol Neurosci Rep. 2013;13:407

4. Baugh CM, Robbins CA, Stern RA, McKee AC. Current understanding of chronic traumatic encephalopathy. Curr Treat Options Neurol. 2014;16:306.

5. Montenigro PH, Baugh CM, Daneshvar DH, Mez J, Budson AE, Au R, et al. Clinical subtypes of chronic traumatic encephalopathy: literature review and proposed research diagnostic criteria for traumatic encephalopathy syndrome. Alzheimers Res Ther. 2014;6:68.

6. Montenigro PH, Corp DT, Stein TD, Cantu RC, Stern RA. Chronic traumatic encephalopathy: historical origins and current perspective. Annu Rev Clin Psychol. 2015;11:309-30.

7. Victoroff J. Traumatic encephalopathy: review and provisional research diagnostic criteria. NeuroRehabilitation. 2013;32:211-24.

8. Jordan BD. The clinical spectrum of sport-related traumatic brain injury. Nat Rev Neurol. 2013;9:222-30.

9. Martland HS. Punch drunk. J Am Med Assoc. 1928;91:1103-7. doi:10.1001/ jama.1928.02700150029009.

10. Omalu BI, DeKosky ST, Hamilton RL, Minster RL, Kamboh MI, Shakir AM, et al. Chronic traumatic encephalopathy in a National Football League player: part II. Neurosurgery. 2006;59:1086-93.

11. Omalu BI, DeKosky ST, Minster RL, Kamboh Ml, Hamilton RL, Wecht CH. Chronic traumatic encephalopathy in a National Football League player. Neurosurgery. 2005;57:128-34.

12. McKee AC, Cantu RC, Nowinski CJ, Hedley-Whyte ET, Gavett BE, Budson AE, et al. Chronic traumatic encephalopathy in athletes: progressive tauopathy after repetitive head injury. J Neuropathol Exp Neurol. 2009;68:709-35. doi:10.1097/NEN.0b013e3181a9d503.

13. McKee AC, Daneshvar DH, Alvarez VE, Stein TD. The neuropathology of sport. Acta Neuropathol. 2014;127:29-51

14. Stein TD, Alvarez VE, McKee AC. Chronic traumatic encephalopathy: a spectrum of neuropathological changes following repetitive brain trauma in athletes and military personnel. Alzheimers Res Ther. 2014;6:4.

15. McKee AC, Robinson ME. Military-related traumatic brain injury and neurodegeneration. Alzheimers Dement. 2014;10:S242-53.

16. Roberts GW, Allsop D, Bruton C. The occult aftermath of boxing. J Neurol Neurosurg Psychiatry. 1990;53:373-8.

17. Hof $P$, Knabe $R$, Bovier $P$, Bouras $C$. Neuropathological observations in a case of autism presenting with self-injury behavior. Acta Neuropathol. 1991;82:321-6.
18. Corsellis J, Bruton C, Freeman-Browne D. The aftermath of boxing. Psychol Med. 1973;3:270-303.

19. Omalu B, Bailes J, Hamilton RL, Kamboh MI, Hammers J, Case M, et al. Emerging histomorphologic phenotypes of chronic traumatic encephalopathy in American athletes. Neurosurgery. 2011;69:173-83.

20. Goldstein LE, Fisher AM, Tagge CA, Zhang XL, Velisek L, Sullivan JA, et al. Chronic traumatic encephalopathy in blast-exposed military veterans and a blast neurotrauma mouse model. Sci Transl Med. 2012;4:134ra60. doi:10.1126/scitranslmed.3003716.

21. McKee AC, Gavett BE, Stern RA, Nowinski CJ, Cantu RC, Kowall NW, et al. TDP-43 proteinopathy and motor neuron disease in chronic traumatic encephalopathy. J Neuropathol Exp Neurol. 2010;69:918-29. doi:10.1097/ NEN.0b013e3181ee7d85.

22. Hazrati LN, Tartaglia MC, Diamandis P, Davis KD, Green RE, Wennberg R, et al. Absence of chronic traumatic encephalopathy in retired football players with multiple concussions and neurological symptomatology. Front Hum Neurosci. 2013:7:222

23. Omalu BI, Bailes J, Hammers JL, Fitzsimmons RP. Chronic traumatic encephalopathy, suicides and parasuicides in professional American athletes: the role of the forensic pathologist. Am J Forensic Med Pathol. 2010;31:130-2.

24. Daneshvar DH, Nowinski CJ, McKee AC, Cantu RC. The epidemiology of sport-related concussion. Clin Sports Med. 2011;30:1-17.

25. Costanza A, Weber K, Gandy S, Bouras C, Hof PR, Giannakopoulos P, et al Review: Contact sport-related chronic traumatic encephalopathy in the elderly: clinical expression and structural substrates. Neuropathol Appl Neurobiol. 2011:37:570-84.

26. Stern RA, Daneshvar DH, Baugh CM, Seichepine DR, Montenigro PH, Riley DO, et al. Clinical presentation of chronic traumatic encephalopathy. Neurology. 2013;81:1122-9.

27. Shen $H$. Researchers seek definition of head-trauma disorder. Nature. 2015;518:466-7.

28. Vonsattel JPG, del Amaya MP, Keller CE. Twenty-first century brain banking. Processing brains for research: the Columbia University methods. Acta Neuropathol. 2008;115:509-32.

29. Vonsattel JPG, del Amaya MP, Cortes EP, Mancevska K, Keller CE. Twenty-first century brain banking: practical prerequisites and lessons from the past: the experience of New York Brain Bank, Taub Institute, Columbia University. Cell Tissue Bank. 2008;9:247-58.

30. Brownell B, Oppenheimer D, Hughes JT. The central nervous system in motor neurone disease. J Neurol Neurosurg Psychiatry. 1970;33:338-57.

31. Love S, Louis DN, Ellison DW, editors. Greenfield's neuropathology. 8th ed. London: Hodder Arnold; 2008.

32. Montine TJ, Phelps CH, Beach TG, Bigio EH, Cairns NJ, Dickson DW, et al. National Institute on Aging-Alzheimer's Association guidelines for the neuropathologic assessment of Alzheimer's disease: a practical approach. Acta Neuropathol. 2012;123:1-11.

33. Braak H, Braak E. Neuropathological stageing of Alzheimer-related changes. Acta Neuropathol. 1991;82:239-59.

34. Mirra SS, Heyman A, McKeel D, Sumi S, Crain B, Brownlee L, et al. The Consortium to Establish a Registry for Alzheimer's Disease (CERAD): Part II. Standardization of the neuropathologic assessment of Alzheimer's disease. Neurology. 1991;41:479-86.

35. Newell KL, Hyman BT, Growdon JH, Hedley-Whyte ET. Application of the National Institute on Aging (NIA)-Reagan Institute criteria for the neuropathological diagnosis of Alzheimer disease. J Neuropathol Exp Neurol. 1999:58:1147-55

36. Hyman BT, Phelps CH, Beach TG, Bigio EH, Cairns NJ, Carrillo MC, et al. National Institute on Aging-Alzheimer's Association guidelines for the neuropathologic assessment of Alzheimer's disease. Alzheimers Dement. 2012:8:1-13.

37. Braak H, Braak E, Bohl J. Staging of Alzheimer-related cortical destruction. Eur Neurol. 1993;33:403-8.

38. McKeith IG. Consensus guidelines for the clinical and pathologic diagnosis of dementia with Lewy bodies (DLB): report of the Consortium on DLB International Workshop. J Alzheimers Dis. 2006;9:417-23.

39. Del Tredici K, Rüb U, de Vos RA, Bohl JR, Braak H. Where does Parkinson disease pathology begin in the brain? J Neuropathol Exp Neurol. 2002;61:413-26.

40. Braak H, Del Tredici K. Invited article: Nervous system pathology in sporadic Parkinson disease. Neurology. 2008;70:1916-25. 
41. Cairns NJ, Neumann M, Bigio EH, Holm IE, Troost D, Hatanpaa KJ, et al. TDP-43 in familial and sporadic frontotemporal lobar degeneration with ubiquitin inclusions. Am J Pathol. 2007;171:227-40.

42. Litvan I, Hauw J, Bartko J, Lantos P, Daniel S, Horoupian D, et al. Validity and reliability of the preliminary NINDS neuropathologic criteria for progressive supranuclear palsy and related disorders. J Neuropathol Exp Neurol. 1996:55:97-105.

43. Dickson DW. Neuropathology of non-Alzheimer degenerative disorders. Int J Clin Exp Pathol. 2009:3:1-23.

44. Bigio EH. Update on recent molecular and genetic advances in frontotemporal lobar degeneration. J Neuropathol Exp Neurol. 2008;67:635-48.

45. Mackenzie IR, Neumann M, Bigio EH, Cairns NJ, Alafuzoff I, Kril J, et al. Nomenclature and nosology for neuropathologic subtypes of frontotemporal lobar degeneration: an update. Acta Neuropathol. 2010;119:1-4.

46. Stamm JM, Bourlas AP, Baugh CM, Fritts NG, Daneshvar DH, Martin BM, et al. Age of first exposure to football and later-life cognitive impairment in former NFL players. Neurology. 2015;84:1114-20.

47. Seichepine DR, Stamm JM, Daneshvar DH, Riley DO, Baugh CM, Gavett BE, et al. Profile of self-reported problems with executive functioning in college and professional football players. J Neurotrauma. 2013;30:1299-304.

48. Robbins CA, Daneshvar DH, Picano JD, Gavett BE, Baugh CM, Riley DO, et al. Self-reported concussion history: impact of providing a definition of concussion. Open Access J Sports Med. 2014;5:99-103.

49. Morris JC, Weintraub S, Chui HC, Cummings J, DeCarli C, Ferris S, et al. The Uniform Data Set (UDS): clinical and cognitive variables and descriptive data from Alzheimer Disease Centers. Alzheimer Dis Assoc Disord. 2006;20:210-6.

50. Corrigan JD, Bogner J. Initial reliability and validity of the Ohio State University TBI identification method. J Head Trauma Rehabil. 2007;22:318-29.

51. Burke WJ, Roccaforte WH, Wengel SP. The short form of the Geriatric Depression Scale: a comparison with the 30-item form. J Geriatr Psychiatry Neurol. 1991;4:173-8.

52. McNair D, Kahn R. Self-assessment of cognitive deficits. In: Ferris NS, Bartus R, editors. Assessment in geriatric psychopharmacology. New Canaan, CT: Mark Powley Associates; 1983. p. 137-43.

53. Roth RM, Gioia GA. Behavior Rating Inventory of Executive Function-Adult Version. Psychological Assessment Resources: Lutz, FL; 2005

54. Patton JH, Stanford MS, Barratt ES. Factor structure of the Barratt Impulsiveness Scale. J Clin Psychol. 1995:51:768-74

55. Marin RS, Biedrzycki RC, Firinciogullari S. Reliability and validity of the Apathy Evaluation Scale. Psychiatry Res. 1991;38:143-62.

56. Cedarbaum JM, Stambler N, Malta E, Fuller C, Hilt D, Thurmond B, et al. The ALSFRS-R: a revised ALS functional rating scale that incorporates assessments of respiratory function. J Neurol Sci. 1999;169:13-21.

57. Pfeffer R, Kurosaki T, Harrah C, Chance J, Filos S. Measurement of functional activities in older adults in the community. J Gerontol. 1982;37:323-9.

58. Walker MP, Ballard CG, Ayre GA, Wesnes K, Cummings JL, McKeith IG, et al. The Clinician Assessment of Fluctuation and the One Day Fluctuation Assessment Scale: two methods to assess fluctuating confusion in dementia. Br J Psychiatry. 2000;177:252-6. doi:10.1192/bjp.177.3.252.

59. Brown GL, Goodwin FK, Ballenger JC, Goyer PF, Major LF. Aggression in humans correlates with cerebrospinal fluid amine metabolites. Psychiatry Res. 1979;1:131-9.

60. First MB, Spitzer RL, Gibbon M, Williams JBW. Structured Clinical Interview for DSM-IV Axis I Disorders, Patient Edition (SCID-I/P version 2.0). New York: Biometrics Research Department, New York State Psychiatric Institute; 1995.

61. Rascovsky K, Hodges JR, Knopman D, Mendez MF, Kramer JH, Neuhaus J, et al. Sensitivity of revised diagnostic criteria for the behavioural variant of frontotemporal dementia. Brain. 2011;134:2456-77.

62. Cleveland Clinic Canada. Headache Intake Questionnaire. Toronto: Toronto Health and Wellness Centre; 2009. http://my.clevelandclinic.org/ccf/media/files/ Canada/Headache intake questionnaire.pdf. Accessed 18 September 2015.

63. Bertens LC, Broekhuizen BD, Naaktgeboren CA, Rutten FH, Hoes AW, van Mourik $Y$, et al. Use of expert panels to define the reference standard in diagnostic research: a systematic review of published methods and reporting. PLoS Med. 2013;10, e1001531

64. McKhann GM, Knopman DS, Chertkow H, Hyman BT, Jack Jr CR, Kawas CH, et al. The diagnosis of dementia due to Alzheimer's disease: recommendations from the National Institute on Aging-Alzheimer's Association workgroups on diagnostic guidelines for Alzheimer's disease. Alzheimers Dement. 2011:7:263-9.
65. Román GC, Tatemichi TK, Erkinjuntti T, Cummings JL, Masdeu JC, Garcia JH, et al. Vascular dementia: diagnostic criteria for research studies. Report of the NINDS-AIREN International Workshop. Neurology. 1993;43:250-60.

66. Gorno-Tempini M, Hillis A, Weintraub S, Kertesz A, Mendez M, Cappa S, et al. Classification of primary progressive aphasia and its variants. Neurology. 2011;76:1006-14

67. Albert MS, DeKosky ST, Dickson D, Dubois B, Feldman HH, Fox NC, et al. The diagnosis of mild cognitive impairment due to Alzheimer's disease: recommendations from the National Institute on AgingAlzheimer's Association workgroups on diagnostic guidelines for Alzheimer's disease. Alzheimers Dement. 2011;7:270-9.

68. Winblad B, Palmer K, Kivipelto M, Jelic V, Fratiglioni L, Wahlund LO, et al. Mild cognitive impairment-beyond controversies, towards a consensus: report of the International Working Group on Mild Cognitive Impairment. J Intern Med. 2004;256:240-6.

69. Armstrong MJ, Litvan I, Lang AE, Bak TH, Bhatia KP, Borroni B, et al. Criteria for the diagnosis of corticobasal degeneration. Neurology. 2013;80:496-503.

70. Kraemer HC. The reliability of clinical diagnoses: state of the art. Annu Rev Clin Psychol. 2014;10:111-30.

71. Dawson-Saunders B, Trapp RG. Evaluating diagnostic procedures. In: Basic \& clinical biostatistics. 2nd ed. Norwalk, CT: Appleton \& Lange; 1994. p. 232-49.

72. Berk RA. Statistical learning from a regression perspective. New York: Springer Science + Business Media; 2008

73. National Football League. NFL grants $\$ 30$ million to National Institutes of Health [press release]. 5 September 2012. http://www.nfl.com/news/story/ 0ap1000000058447/article/nfl-donates-30-million-to-national-institutes-ofhealth. Accessed 18 September 2015.

74. National Institutes of Health. NIH and NFL tackle concussion research [press release]. 16 December 2013. http://www.nih.gov/news/health/dec2013/ ninds-16.htm. Accessed 18 September 2015.

75. U.S. Department of Defense. DOD establishes first brain tissue bank to study traumatic brain injury in service members [press release 434-13]. 13 June 2013. http://archive.defense.gov/releases/release.aspx?releaseid=16094. Accessed 18 September 2015

76. Gabel MJ, Shipan CR. A social choice approach to expert consensus panels. J Health Econ. 2004;23:543-64.

77. Blacker D, Albert MS, Bassett SS, Go RP, Harrell LE, Folstein MF. Reliability and validity of NINCDS-ADRDA criteria for Alzheimer's disease: the National Institute of Mental Health Genetics Initiative. Arch Neurol. 1994;51:1198-204.

78. Kiernan PT, Montenigro PH, Solomon TM, McKee AC. Chronic traumatic encephalopathy: a neurodegenerative consequence of repetitive traumatic brain injury. Semin Neurol. 2015;35:20-8.

79. Gavett BE, Stern RA, Cantu RC, Nowinski CJ, MCKee AC. Mild traumatic brain injury: a risk factor for neurodegeneration. Alzheimers Res Ther. 2010;2:18.

80. Maroon JC, Winkelman R, Bost J, Amos A, Mathyssek C, Miele V. Chronic traumatic encephalopathy in contact sports: a systematic review of all reported pathological cases. PLoS One. 2015;10, e0117338.

81. Stein TD, Montenigro PH, Alvarez VE, Xia W, Crary JF, Tripodis Y, et al. $\beta$-amyloid deposition in chronic traumatic encephalopathy. Acta Neuropathol. 2015:130:21-34

\section{Submit your next manuscript to BioMed Central and take full advantage of:}

- Convenient online submission

- Thorough peer review

- No space constraints or color figure charges

- Immediate publication on acceptance

- Inclusion in PubMed, CAS, Scopus and Google Scholar

- Research which is freely available for redistribution 